\title{
SELECTION OF SURFACE TO SURFACE RUDAL KRI-KERAMBIT CLASS USING DEMATEL AND ANALYTIC NETWORK PROCESS METHODS
}

\author{
Supartono ${ }^{1}$, Joko Purnomo ${ }^{2}$, Siswo Hadi Sumantri ${ }^{3}$, Wishnu Krestiawan ${ }^{4}$. \\ ${ }^{1}$ Indonesia Defense University, Unhan Jakarta Indonesia \\ 2,3,4 Indonesia Naval Technology College, STTAL Surabaya Indonesia
}

\begin{abstract}
Indonesian Warship (KRI) is one of the Main System Weapons (defense equipment) owned by the Navy. In its 2017 procurement, the Navy made a second generation Fast Ship Missile (KCR) made by PT PAL that produced more than the previous generation, both in terms of capacity and rich ships, named KRI Kerambit Class. To support the battle, this KRI Kerambit Class will be equipped with a surface to surface missile (SSM) to improve the ability to use maximum battleships. To be able to activate its function properly, it is necessary to choose the right missile base weapon. The selection of alternative missile weapons over water requires analysis of information and collects important requirements about data from alternative weapons over the air. In addition to alternatives, it is expected that major criteria will be considered in the selection of the Weapons over the air. In making the decision to procure Weapons Over Water, where the conflict cannot be arranged in the form of a hierarchy because it requires interaction and higher level elements to lower level elements. Therefore in this study the Trial Making and Evaluation Laboratory (DEMATEL) and Analytic Network Process (ANP) methods have the ability to accommodate the interrelations between criteria or alternatives. Based on data processing, the Exocet MM 40 Block 3 has been selected. This missile has several advantages compared to other missiles, including launching at counters and missfire that is very low and has very good durability.
\end{abstract}

Keywords: Missile Selection, DEMATEL, Analytic Network Process.

\section{INTRODUCTION}

Geographically, the Republic of Indonesia is a country known as the largest archipelago in the world, Indonesia has 16,056 (Budy, 2019) islands from Sabang to Merauke. Large islands in Indonesia include Sumatra, Kalimantan, Java, Sulawesi and Irian Jaya and a series of islands are also referred to as the archipelago or the Indonesian archipelago.

Judging from the number of islands scattered both large and small islands where the sea as a separator. So a very strong concept of marine defense is needed to maintain the upholding of the sovereignty of the Unitary Republic of Indonesia in order to realize national development goals that apply for all time based on Pancasila and the 1945 Constitution.

With this vast territory of Indonesian waters demanding the Indonesian government to build strong sea power to maintain the integrity of the Unitary Republic of Indonesia. This is intended to protect various potential threats that will occur in the territorial waters of Indonesia, both potential threats from within and potential threats from outside the Republic of Indonesia. Defense forces in the maritime field that are reliable, strong and fast are the core of defense readiness for the TNI in general and the Navy in particular. The Indonesian Navy in this case is very directly related to the defense of the maritime sector, it is highly demanded to always be prepared to maintain security throughout the archipelago sea.

Government efforts in increasing defense must be supported by sophisticated and modern defense equipment. As we know, the real condition of existing defense equipment is very far as expected due to limitations or shortcomings in terms of both the number and sophistication of defense equipment that seems to run in place and seemed to experience technological setbacks. This can be seen from the old defense equipment that is out of date without following the regeneration of defense equipment that should be continuous and sustainable. The existence of defense equipment is 
a necessity for every country. And because of its strategic function, defense equipment always demands superior technology. Even for standardization of equipment until there is specifically for the military. The Indonesian Navy's current strengthened defense system has been urged through addition and rejuvenation. Modernization of the latest technological defense equipment supported by the ability of electronic warfare must begin to show its form of strength.

In Law Number 34 of 2004 Concerning TNI Article 9, the Navy is tasked with: Carrying out the duties of the TNI maritime force in the field of defense, enforcing the law and maintaining security in the sea territory of national jurisdiction in accordance with the provisions of national law and international law which have been ratified, carrying out the task Navy diplomacy in the framework of supporting foreign policy set by the government, carrying out the tasks of the TNI in the development and development of the strength of the sea dimension, carrying out the empowerment of sea defense areas.

In addition to referring to Article 9 of Law Number 34 of 2004 above, the Indonesian Navy also has a doctrine called the Navy's Eka Sasana Jaya Doctrine. The Indonesian Navy's Eka Sasana Jaya doctrine which is an application of the Nusantara Sea Defense Strategy (SPLN) states that: Deterrence Strategy, Layered Defense Strategy, Sea Control Strategy (Dalla).

To prepare for preparedness, the Indonesian Navy has a method as a marine security defense force that has a combat tool and its supporting facilities that are projected in the Integrated Armed Weapon System (SSAT) with one of its components the Republic of Indonesia Warship (KRI). With the SSAT method approach that leads to the policy of the Navy's Development Program in the form of the Minimum Main Force (MEF) which is a power that is designed to have certain abilities, to face threats in order to protect and protect the country's sovereignty, the safety of the whole nation and the integrity of the Unitary Republic of Indonesia. With the possibility of risk that will be faced when the threat is greater than the ability to be designed. In terms of quantity, the TNI's main weaponry system has actually reached a minimum basic strength, so that the functions of the Indonesian Army main weaponry system are still far from the MEF.

Thus, rejuvenation of existing defense equipment and procurement of new defense equipment needs to be done to meet MEF. One of the beating forces was in the Republic of Indonesia Region I Fleet Fast Boat Unit, the Indonesian Warfare Class KCR (KRI) Kerambit, a KCR type ship made by PT PAL, Indonesia, located in Tanjung Perak, Surabaya, in 2018 .

KCR type KRI class ship Kerambit (Batch 2) is designed in such a way as to be able to carry out combat tasks and security assistance tasks. Factors of mobility, destruction of destructive power and the ability of the command control system with elements of ships on water and aircraft make the KCR ship a reliable ship for water to be able to carry out the tasks of marine operations. The 60meter Missile Fast Ship has the ability as a fast missile boat as well as a patrol ship killer with special hit and run capabilities in attacking and destroying targets on the surface (AKPA) including Anti-FPB tactics and being able to carry out defenses against air attacks (Hanud) in order uphold the sovereignty of the territory of the Republic of Indonesia. However, the KRI has not yet been installed with a Surface to Surface Missile as one of the weapons in anti-surface warfare. The main task of the KRI-Kerambit class ships (according to the tactical manual for the use of KCR-type KCR ships, the Navy Headquarters general publications of the Navy (strong - 130,102) is to carry out anti-ship battles on water and ship fire Assistance. While the additional functions of 
KCR ships are organizing combat security and sea security assistance.

To be able to carry out its functions properly, one way is to choose a good SSM (Surface to Surface Missile) missile, so an alternative selection of SSM missile weapons is needed. The selection of alternative missile weapons for water requires an analysis of information and identification of various important requirements regarding data from alternative weapons for water which broadly encompass operational requirements oriented to: Geographical Conditions of the Unitary State of the Republic of Indonesia, Concept of the Defense of the Islands of the Nation, Defense of the Weapons strategic.

These conditions can cause problems and constraints when alternatives are found that have a good value in certain criteria (such as control chain equipment), but lacking in other criteria (such as sensor equipment). And conversely, alternatives are lacking in the control chain equipment criteria, but are good in the sensor equipment criteria. In addition to these conditions, there is a condition where there is a close relationship between criteria one with other criteria, for example political criteria will affect the procurement criteria and embargo of missile parts.

Given the conditions mentioned above, this thesis research is expected to help provide advice and input to the leadership of the Navy in objectively choosing missile weapons over water. The method used in this thesis research is the Decision Making Trial And Evaluation Laboratory (DEMATEL) and Analytic Network Process (ANP) where the DEMATEL method can change the relationship between cause and effect of criteria into a structured model system that is easily understood (Tzeng, 2007). This is done to get consideration of decision making by knowing the interrelationships between criteria or aspects. While the ANP method is used to determine the value of alternative priority weights of management system attributes that are identified based on the model obtained from the DEMATEL method. The ANP method is the development of the Analytic Hierarchy Process (AHP), whereas the AHP method does not discuss the inner-dependence between the criteria, because the AHP method is hierarchical (Saaty, 2001).

By paying attention to the existing conditions and reality as explained in the background, a problem statement can be formulated, namely: "How to choose a Surface-to-Surface Surface Missile Weapon System for Kerambit Class Missile Ship (KCR)."

Furthermore, to answer the problem statement above, the reseach questions are described as follows:

a. How is the decision making model for the missile selection made in the Kerambit Class ship?

b. How do you determine the missile criteria and sub-criteria for Class Kerambit vessels?

c. How do you determine the priority of the Surface-to-Surface (Missile) Weapon Control System for KRI Kerambit class KRI?

The purpose of this study are:

a. Determine the model of decision making for the selection of missiles on Kerambit class vessels.

b. Determine the criteria and sub-criteria for missile class Kerambit Class ships by considering various criteria and sub-criteria.

c. Determine alternative priorities for the selection of missiles over water on Class Kerambit vessels.

Because there are many factors that influence the selection of the type of missile, the scope of the problem is limited to the selection of Surface-to-Surface (Missile) Weapon Control System for the Kerambit Class KCR ship owned by the Navy with the assumption that this system has fulfilled the essential functions of the ship Kerambit Class KCR. 


\section{Material and Methods}

Chapter II contains theories relating to and underlying existing problems, in this case relating to the Kerambit Class of the Republic of Indonesia Ship, Multi Criteria Decision Making, Decision Making Trial and Evaluation Laboratory, Analytic Network Process

\subsection{Indonesian Kerambit Class Ship}

Battleships are ships used for military or armed forces interests. Generally divided into aircraft carriers, combatant ships, patrol vessels, transport ships, submarines and support vessels used by the navy such as tankers and tender ships. The presence of warships began when many kingdoms or governments needed or felt the need to assert their position in the waters while providing security guarantees in the waters to protect their country and its activities such as fishing and trade. Many security disturbances in the waters must be prevented, including attacks from other countries which are safer when directly deterred from the sea.

Combat ship (combatant ship) is an armed warship commonly owned by the navy which is used for direct combat at sea. Generally armed with cannons, anti-air attack cannons, anti-air attack, anti-submarine missiles, and against targets on land, torpedoes, mines, even cruise missiles.

Warship in Indonesia is abbreviated as KRI which is an extension of the Republic of Indonesia ships. KRI Kerambit Class is a Fast Missile Ship (KCR) which is one of the types of ships of the Republic of Indonesia Warship with a Fast Missile Ship type that is manufactured at PT PAL, Ujung Surabaya. KRI Kerambit is a fast reaction hitting ship which in carrying out its duties prioritizes the element of eradication, carries out the mission of attacking quickly, destroying the target at one time and avoiding the opponent's attack in a short time too. The ship, measuring 60 meters long, 8.10 meters wide, and weighing 500 tons, has a reliable propulsion system capable of sailing and maneuvering at a speed of 28 knots.

\subsection{Multiple Criteria Decision Making (MCDM)}

Multi-Criteria Decision Making (MCDM) is a decision-making method consisting of theories, processes, and analytical methods for decision making that involve uncertainty, dynamics, and multi-criteria aspects of decision. Multi-Criteria Decision Making (MCDM) is the terminology used in solving problems where the MCDM approach is expected to get the best alternative.

Problems with multiple criteria may be defined as a situation where a criterion is considered to choose an alternative used to:

a. Determine the best alternative or a collection of the best alternatives (problem choice).

b. Ranking alternatives from best to worst (ranking problems), or

c. Divide alternative sets into alternative subsets based on several rules (sorting problems).

In MCDM, the use of conventional optimization methods is generally limited to only one selection criterion, where the selection taken is the choice that best meets the objective function. But the problems faced, especially those that are more practical, are not that simple. There are times when subjective considerations must be included in the decision making process.

MCDM provides an alternative to utilize objective and subjective considerations as a basis for decision making. There are two groups in MCDM, namely the decision-making group based on the selected attribute or often known as the Multiple Attribute Decision Making (MADM) and the group based on the synthesis of the choice attribute or often referred to as Multi-Objective Decision Making (MODM).

Multiple Objective Decision Making (MODM) uses an optimization approach, so to solve it must be sought first mathematical model of the problem 
to be solved. Then only maximized or minimized according to the mathematical model that has been obtained. Whereas the Multiple Attribute Decision Making (MADM) uses a selection approach by first determining the quantitative and qualitative attributes of the components to be selected.

\subsection{Decision Making Trial and Evaluation Laboratory (DEMATEL)}

The DEMATEL method is the most important application applied in multi criteria decision making (MCDM) to visualize and build relationships between criteria and sub-criteria such as, Evaluating and Selecting suppliers (Shahryar, 2012), Evaluating suppliers on an ongoing basis (Chiou, 2011), prioritizing distribution centers in the supply chain (Elham, 2012) Apart from the results of the final step of DEMATEL (IRM) can be used in the fuzzy approach to evaluate the level of super additive efficiency after determining the relationship between criteria and also it can be combined with other multi criteria decision making methods such as , Analytic Hierarchy Process (AHP) Analytic Network Process (ANP) (Saaty, 1996) to measure the dependency and feedback relationship between certain criteria, VIKOR and Technique for Order Performance by Similarity to Ideal Solution (TOPSIS).

This method can be done by following the following five steps:

a. Creating a relationship matrix is directly related directly to the matrix.

b. Calculates the normalization in a direct linkage matrix

c. Calculates the relationship matrix in total.

d. Obtain an inner dependence matrix and map the impact of the relationship.

e. Get an inner dependence matrix. In this step, the sum of each column of relationships in total $n \times$ $\mathrm{n}$ matrices is equal to 1 with the normalization method and then the inner dependence matrix can be acquired.

\subsection{Analitycal Network Process (ANP)}

Saaty (2003 in Aan Rusdiana (2012)). Analytic Network Process (ANP) is a general theory of relative measurement used to derive composite priority ratios from individual ratio scales that reflect relative measurements of the influence of interacting elements with regard to control criteria.

ANP uses networks without having to set levels as in the hierarchy used in the Analytic Hierarchy Process (AHP), which is the starting point of ANP. The main concept in ANP is influence, while the main concept in AHP is preference. AHP with its dependency assumptions about clusters and elements is a special case of ANP. ANP is a new approach in the decision making process that provides a general framework for treating decisions without making assumptions about the independence of elements at a higher level than elements at a lower level and about the independence of the elements in a level.

ANP is a combination of two parts. The first part consists of a hierarchy of controls or networks of criteria and sub-criteria that control interactions. This control does not need a hierarchical structure like the AHP method. The second part is a network of influences between elements and clusters.

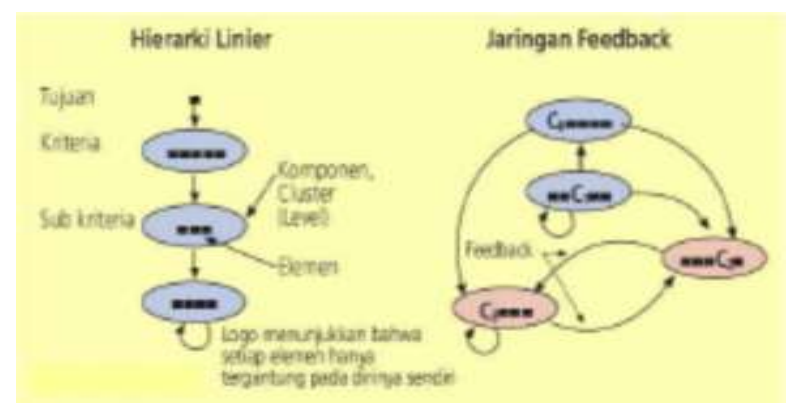

Fig.1 Differences in Hierarchy and Networks

\section{RESULT AND DISCUSSION}

This chapter will explain the steps in collecting data needed in this research. Data collected and processed include data on the value 
of direct linkages between criteria based on the purpose of choosing surface-to-surface missiles and data on the relationship between elements of criteria either inner dependence or outer dependence and the relationship between criteria and alternatives by means of pairwise comparison between criteria and alternative surface missiles to surface owned by the Navy.
The criteria developed are related to the factors that influence the decision to choose a missile weapon that will be considered to strengthen the KRI. By considering the opinions of various sources both from the missile weaponry experts and their users and the existing literature, in this study the following criteria were developed:

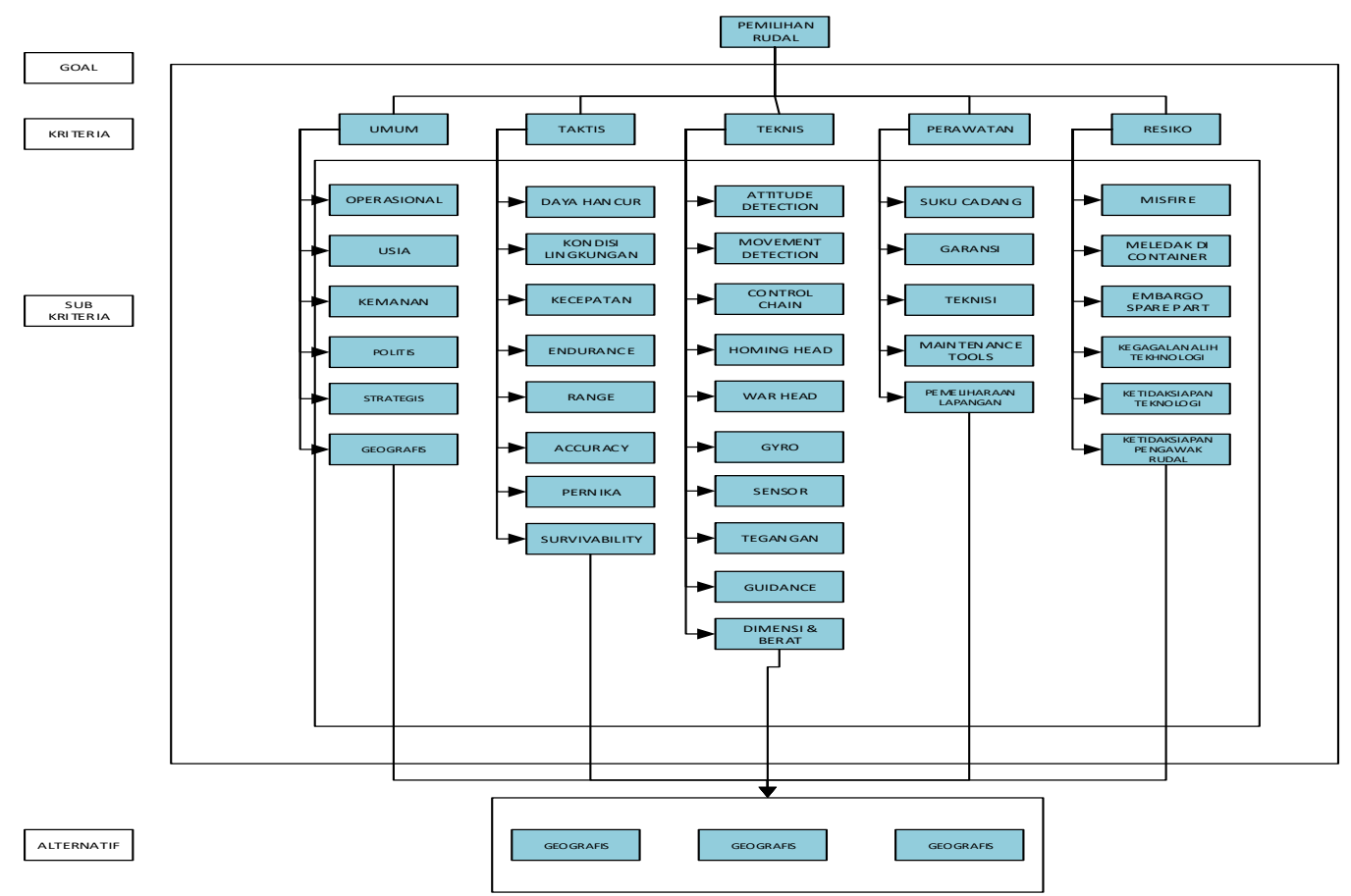

Fig.2 Model Criteria for Selection of Surface-to-Surface Missile to be tested

In this research, the object is surface-tosurface missiles that the Navy has:
a. Exocet MM 40 Block 3 Missile
b. Missile C 705
c. Missile C 802

\subsection{DEMATEL Data Collection and}

\section{Processing in Criteria and Sub-Criteria}

This DEMATEL method is applied to find out the interrelation picture in the criteria and subcriteria in the selection of alternative sales strategies. The data entered was obtained from a questionnaire filled out by those who were considered experts in the clothing business. So we get an impact-relation map (IRM) on the final result, which is normalized, a total matrix of interrelationships between criteria. To make a value matrix the basis for making a model on ANP. In this processing there are several stages, starting from looking for a matrix of values of direct linkages between criteria, a linkage value matrix that has been linked in the normalized formula

$$
M-\dot{x} .1
$$

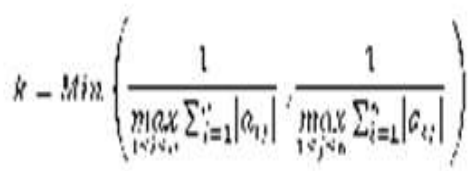


Data processing using the Decision Making Trial And Evaluation Laboratory (DEMATEL) method consists of several stages (Puspitasari, 2012).

The stages are:

a. Step 1: Combine the values of the direct relationship matrix that the experts have filled in using the average value.

b. Step 2: Normalize the linkage matrix directly by multiplying the values in each column by the total value of the sum of the values for each row.

c. Step 3: Obtain a total interconnectedness matrix by subtracting each column of the identity matrix values from the normalized matrix, followed by processing with minverse and mmult.

d. Step 4: Calculate the dispatcher group and receiver group. The dispatcher group and receiver group are obtained by determining the values of $D$ and $R$ first. The $D$ value is obtained from the sum of the value rows in the matrix that has been processed with mmult. Whereas the $R$ value is obtained from the number of column matrix values after the mmult process.

e. Step 5: Set a threshold value and get an impact-diagram map.

Tabel 1. MMULT

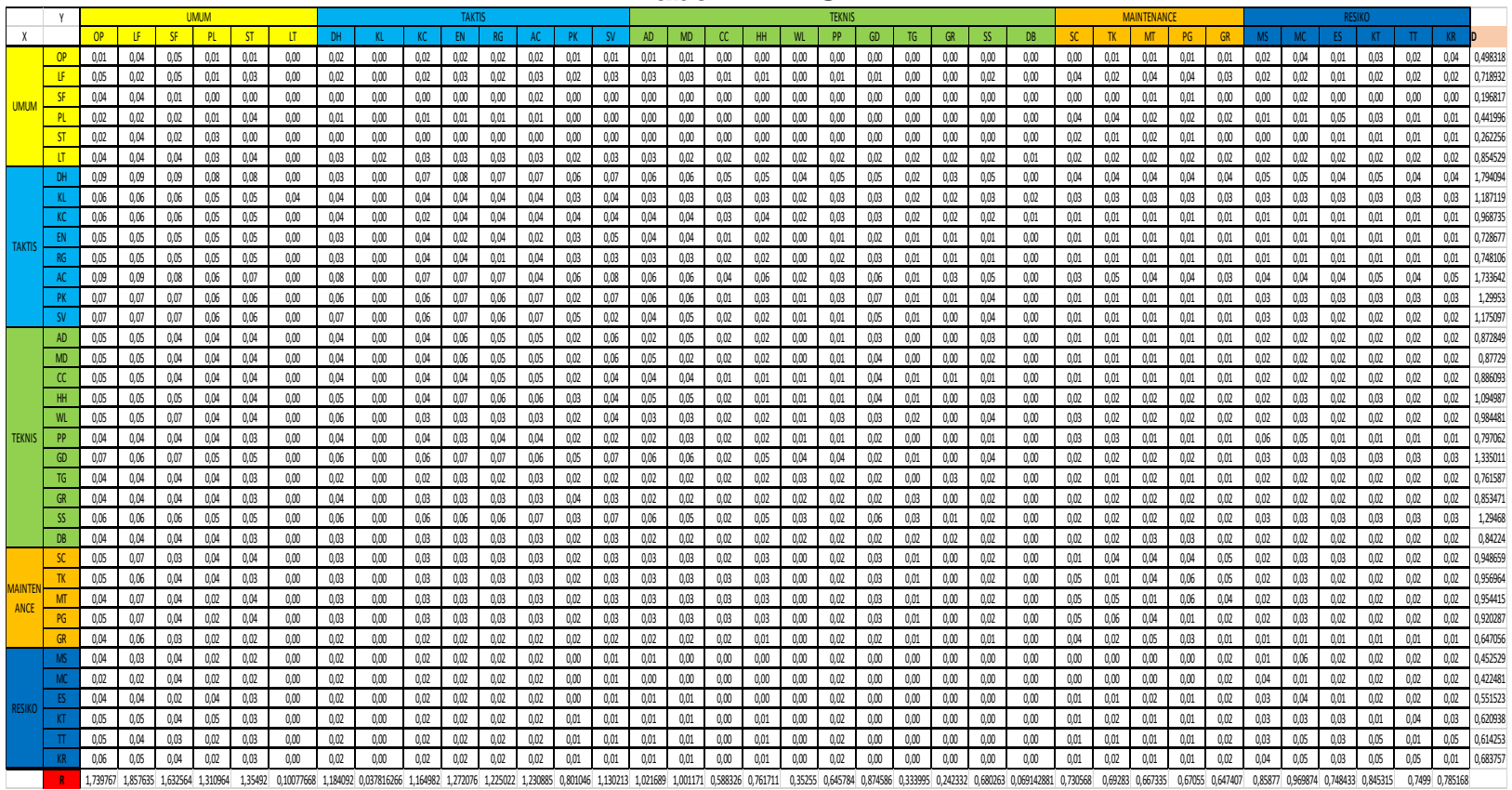

Table 2. Dispatcher dan receiver Subcriteria.

\section{IMPACT DIAGRAPH}

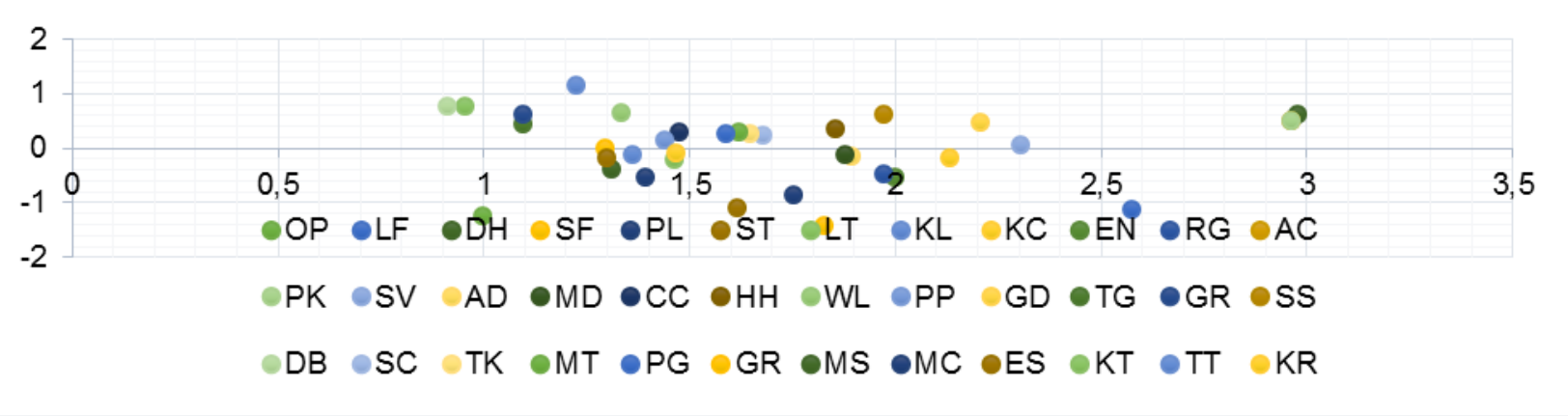

Fig.3 Impact Diagraph Map 
The mmult matrix results show the relationship between one sub-criteria and the other sub-criteria. To find out if there is a relationship between one sub-criterion with other sub-criteria, it is necessary to determine the threshold value of the value first. Threshold value can be found in two ways; namely: Take the average value of the results table mmult results and can be determined through expert opinion.

In this study, the value of the Treshold Value is determined by the average value of the results of the mmult table of 0.0239 . Matrix column values that are equal to or greater than the Treshold Value values in the mmult matrix are colored green, while smaller ones remain colored gray-blue. A green value indicates that the subcriteria in the row affect the sub-criteria in the column. While for white, the sub-criteria in the row do not affect the sub-criteria in the column.

Table 3. Matrix of Results Mmult with Threshold Value
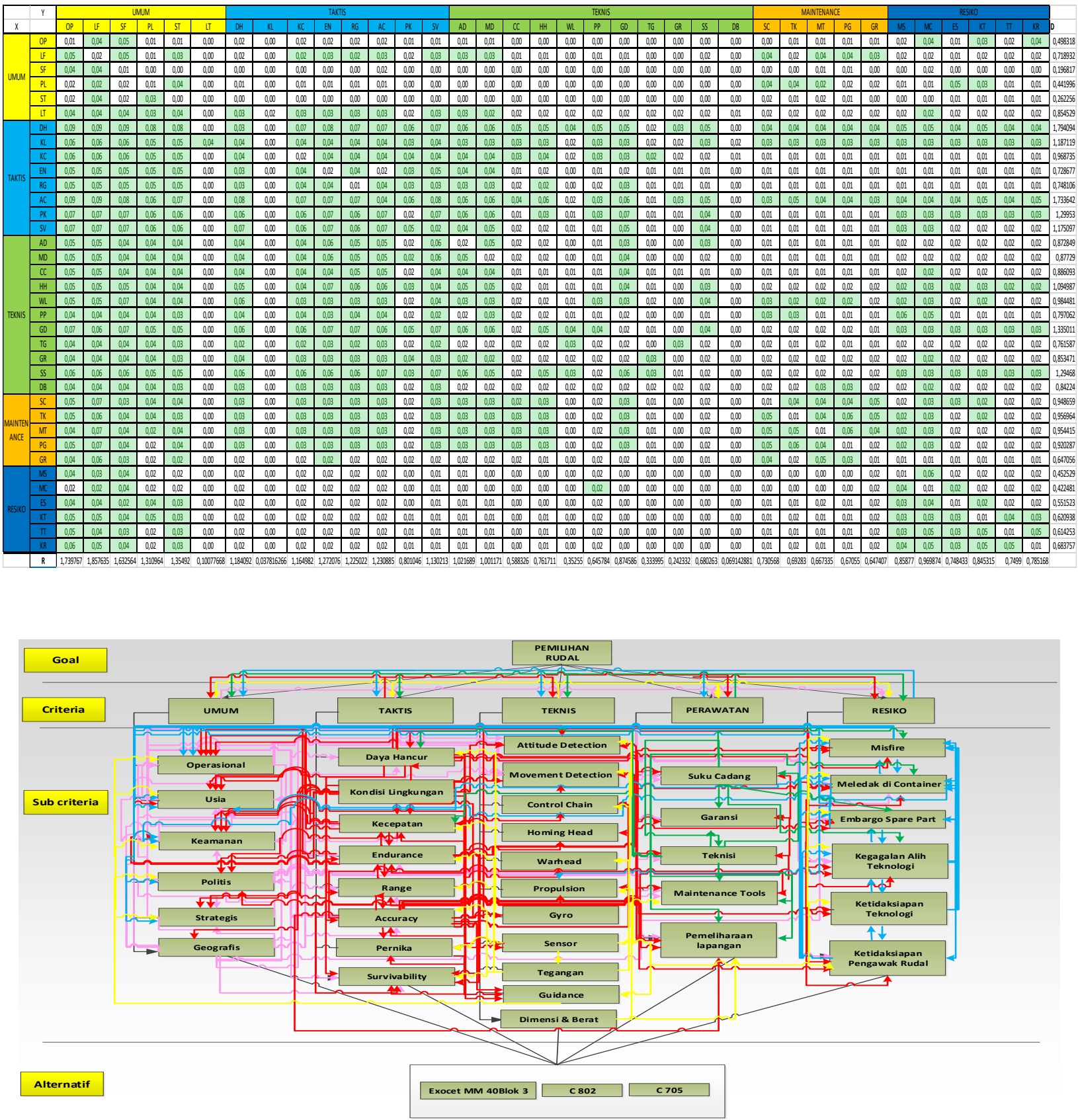

Fig.4 ANP Network with Innerdefendence and Outerdefendence 


\subsection{ANP Data Processing}

ANP network models are made with super
Next is the ANP network model display in the super decision software

decision software and are based on impact maps.

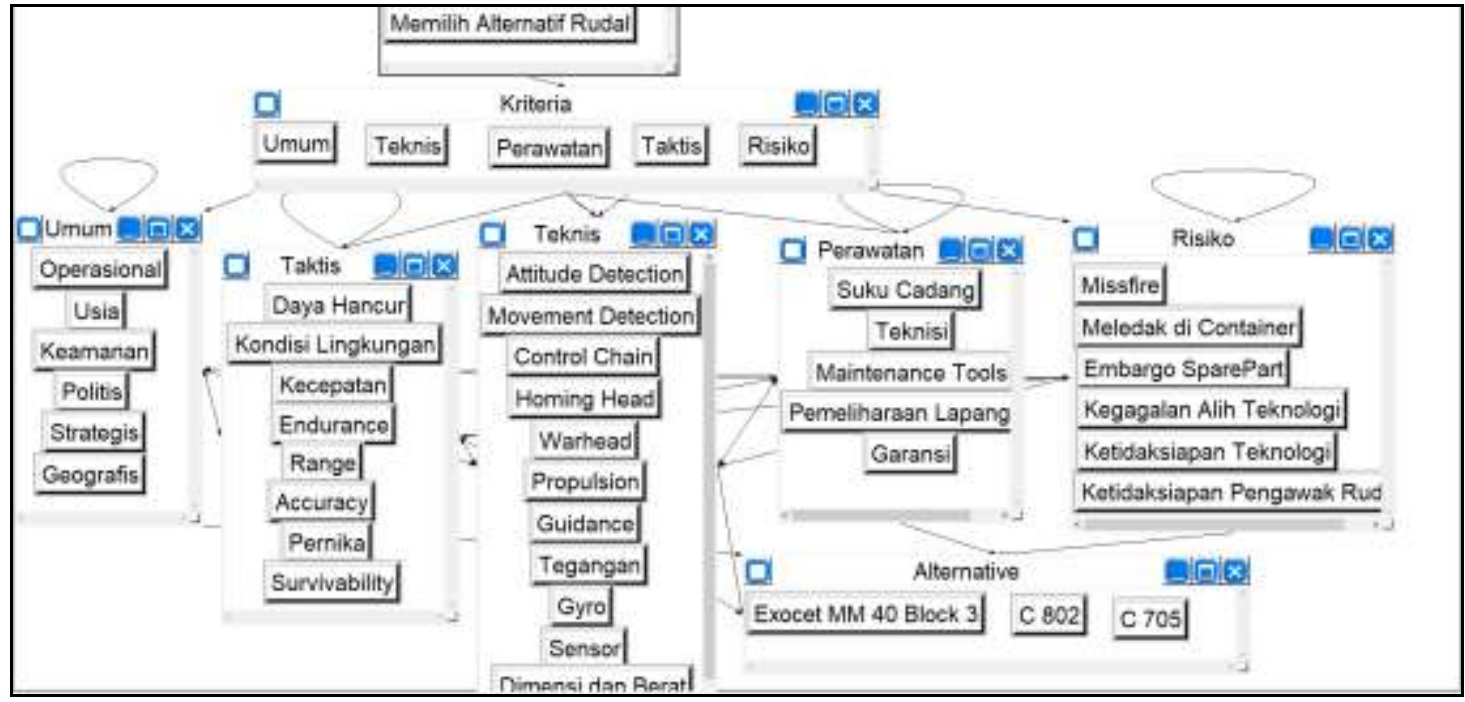

Fig.5 Model Criteria, Sub-Criteria, and Alternative Selection of SSM Missiles on KRI

After the network model has been created, then the pairwise comparison value can be determined between the criteria and between alternative management system attributes for each category. The pairwise comparison value was obtained using a questionnaire. The priority weight value for each category obtained based on pairwise comparison values will be compared to get the final priority weight value. From the data processing on the Super decision software, the alternative priority weighting for missile selection is obtained:

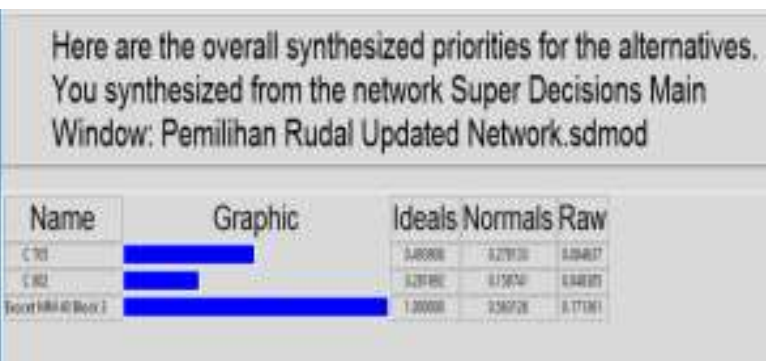

Fig.6 Ranking of Missile priorities

Table 4. Ranking of Missile priorities

\begin{tabular}{|l|l|c|}
\hline \multicolumn{1}{|c|}{ Rank } & \multicolumn{1}{|c|}{ Missile Name } & Weight \\
\hline 1 & Exocet MM 40 Block 3 & 0,563126 \\
\hline 2 & C 705 & 0,278133 \\
\hline 3 & C 802 & 0,158741 \\
\hline
\end{tabular}

\subsection{Analisis Sensitifitas}

Basically, the results of previous calculations describe an ideal state. To anticipate changes from the forecasts that have been made previously, a sensitivity analysis is carried out on these estimates. Sensitivity analysis is carried out to determine the stability of the priorities of the alternatives. Sensitivity analysis is performed using Super decision 2.1.0 software by changing the weight value in the alternative. So it was found that by changing the value of the weight values on the alternative will affect the results of the original ranking or not. When there is a ranking change, the change is called the critical point of an alternative. Following are the results of the sensitivity analysis of data calculation from the selection of surface to surface missiles on KRI.

The vertical line shows the weight value for each indicator to be tested for sensitivity, while the horizontal dotted line is an interval indicator for changes in the weight value for each alternative. In this study, the sensitivity analysis conducted is to use the Superdecisions software is to change the value of weights on the alternatives and nodes that are tested. 


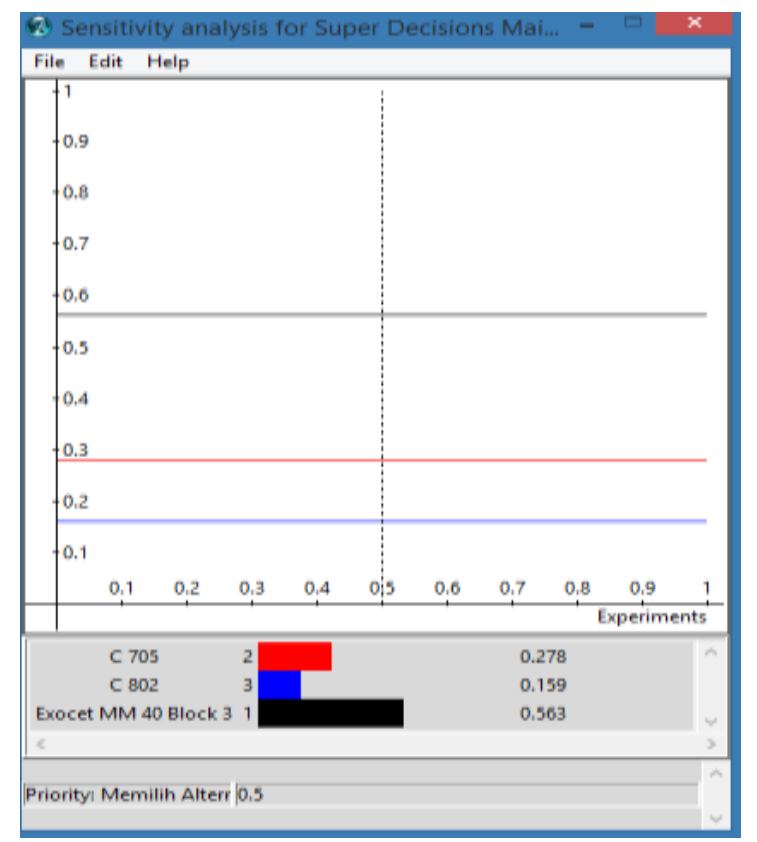

Fig.7 Analysis of Alternative Sensitivity of MM 40 Exocet Missiles in Block 3

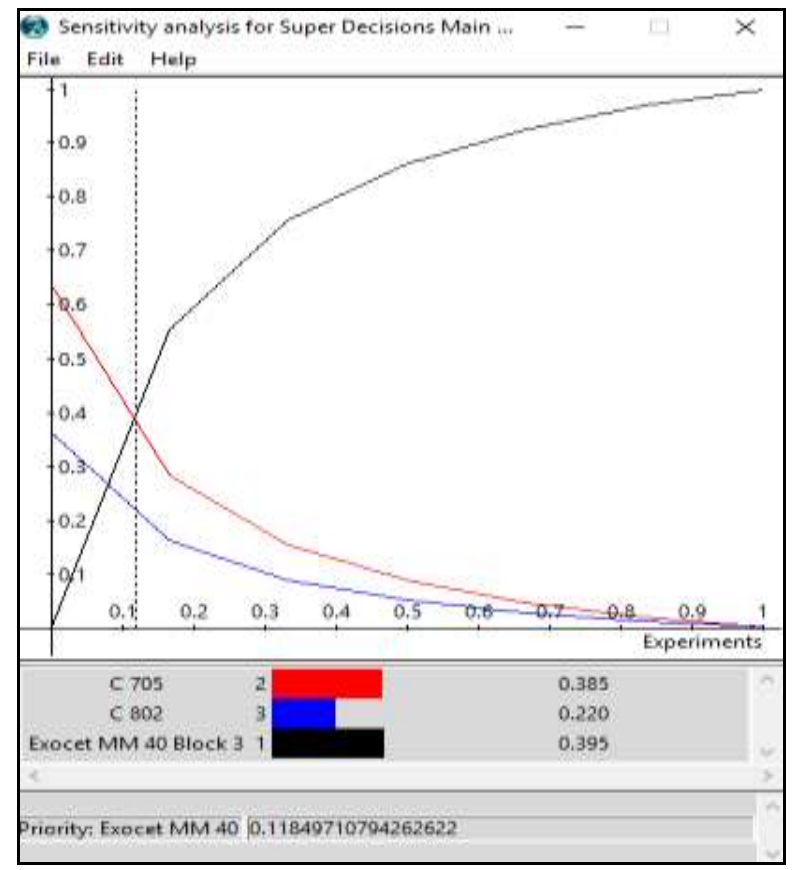

Fig.8 Analysis of Operational Node Work Sensitivity

In this Sensitivity Analysis will be known by changing the value of the weights on the alternative or node that is tested will affect the results of the original ranking or not. Whenever there is a point where ranking / priority changes occur, that point is called the critical point of an alternative or node. An example can be seen in Figure 4.18 which shows a sensitivity test on an alternative Exocet MM 40 Block 3 Missile that produces a critical weight value of 0.118497 . While for the Operational node, there is no critical point that can cause changes in ranking / priority, as well as other nodes. The results of the sensitivity analysis of all nodes that cannot cause changes in ranking / priority of alternatives, prove that this model is strong and not affected by changes.

\section{CONCLUSION}

From the results of data collection and processing, as well as analysis and interpretation of the results of data processing that have been done, the conclusions that can be drawn in this thesis are:

a. Because in the selection of priority surfaceto-surface missile selection on the KRI Class Kerambit is very complex, so the DEMATEL and ANP methods can be obtained by models in decision making that clearly describe the relationship between criteria and sub-criteria.

b. The main criteria to be considered in the selection of alternative surface-to-surface missiles for KRI Kerambit type vessels are General criteria, then the second to fifth consecutive priority is Maintenance, Risk, Tactical, and finally Technical criteria. While the main sub-criteria that are being considered in the selection of alternative surfaceto-surface missiles for KRI Kerambit vessels are exploding sub-criteria in containers. For the second to fifth priority in a row are missfire, missile manners unpreparedness, failure of technology experts and endurance.

c. The alternative selection of surface to surface missiles on the $\mathrm{KRI}$ of the chosen Kerambit Class is the one who gets the biggest value from calculations using the Super Decision Software, the Exocet MM 40 Block 3 missile with a priority weighting value of 0.563126 and then sequentially the second alternative priority in the selection of surface missiles to the surface is the C-705 missile with a priority weight value of 
0.278133 and as the last priority of the three alternatives there is a C 802 missile with a priority weight value of 0.158741 .

\section{FUTURE WORK}

Suggestions that can be put forward in writing this research as well as for further research are:

a. Based on the results of the surface to surface missile selection process on the Kerambit Class $\mathrm{KRI}$ using the combined DEMATEL and ANP methods above, for the development of KRI strength, the Exocet MM 40 Block 3 missile is the best alternative to the available options.

b. Suggestions for decision making in the procurement of missiles to pay more attention to the criteria that are important in the procurement of defense equipment so that the goal of realizing the Minimum Essential Force can be achieved.

c. In this study only accommodates experts in the fields of procurement, education and training, maintenance and maintenance as well as operational. Suggestions for further research should be added by planning and material experts (Srenal and Dismatal).

\section{REFERENCES}

Agus, R. 2011. Research Methodology Textbook. Jakarta: EGC.

Amiri, M. S. 2011. Manage. Developing a DEMATEL method to prioritize distribution centers in the supply chain, 10 (3-4): 27928.

Arikunto .2016. Research Procedure: A Practical Approach PT. Rineka Cipta. Jakarta:

Arlina. 2015, September 25). Economics. Taken back from the Basics of Decision Making: http://www.ilmu-ekonomiId.com/2018/09/dasar-dasar-pengambilkep..html?m=1

Boyokyazici, M. d. 2003. The Analytic Hirearchy Process and ANP. Hacettepe Journal of Mathematics and Statistics, 65-73.

Budy, V. 2019, June 12. The number of islands in Indonesia has decreased to 16 thousand.
Taken back from Databoks: http://www.databoks.katadata.co.id

Cahyono, D. W. 2017. Systems analysis and operations research. Analysis of Selection of Patrol Vessels in Indonesian Waters with the Integration of Life Cycle Cost and MCDM Methods, 15.

Chiu (2006). Y.J., H.C. Chen, J.Z. Shyu and G.H. Marketing strategy based on customer behavior for the LCD-TV. Int. J. Manage. Decision Making, 7 (2-3): 143-145.

Chou, C. 2009. Expert Systems With Application. Selecting Management Systems for Sustainable Development in SME's: A hybrid novel model based on DEMATEL and $A N P, 144-158$.

Elham 2012. DEMATEL. Applied Sciences, Engineering and Technology, 5 (13).

Elham (t.y.). DEMATEL. Research j.

Hori, S., \& Shimizu. (1999). Control Engineering Practice. Designing methods of human interface for supervisory control systems, 7 (11), 1413-1419.

Hsien Tsai, W. d. 2009. Selecting Management System for sustainable development in SMEs. A novel Hybrid model based on DEMATEL, ANP and ZOGP, 36.

Kobangdikal. 2004. Integrated Armada Weapon System Instructions Package. Surabaya.

Maulana, A. 2015. Systems Analysis and Operations Research. Analysis of the Selection of the Indonesian Navy's Alutsista with the Life Cycle Cost Method and the ANP Method, 20-27.

Najib, R. 2015. System Analysis and Operations Research. approach of Fuzzy MCDM for the Selection of Air Strike Determination Weapons for the KRI MAKASAR Class LPD Vessels, 1-13.

Naser 2010. M.,. High Intensity Interior Aircraft Noise Increase The Risk Of High Diastolic Blood Pressure In Indonesia Air Force Pilots, 276-282.

Purwanto, B. R. 2015. Systems Analysis and Operations Research. Navy Submarine Analysis with the Decision Making Trial And Evaluation Laboratory (DEMATEL) Method and Analytic Network Process, 23-34.

Riza, A. 2012. Analysis of the Effect of Capital Adequacy Ratio. Makasar. 
Saaty. 1996. Decision making with dependence and feedback: Analytic network. Pittsburgh: RWS.

Saaty. 1999. Fundamentals of The Analytic Network Process. Pittsburgh: RWS.

Saaty. 2001, July 2. Models, Methods, Concepts and Applications of the Analytic Hierarchy Process. Retrieved from Kluwer Academic Publichers: http://www.dx.doi.org

Saaty. 2004. Decision Making - The Analytic Hierarchy and Network. Pittsburgh: RWS. Publication

Santosa. 2008. Physiology and Biochemistry of Commodities in the Harvest of Hoticulture. Yogyakarta: Canisius.

Setioko. 2013, April 19. Decision Making in Organizations. Taken back from decision making in organizational behavior: http://www.belamy19.blogspot.com/2013/04 /makingdecisions-in-
Shahryar. 2012. S., A. Aireza, S. Meysam and F. Elham, 2012. Interrelation study of entrepreneur's capability, 17 (7): 818-820.

Shimizu, H. S. 1999. Control Engineering System. Designing Method of Human Interface for Supervisory Control System, 1413-1419.

Sugiyono 2008. Qualitative Quantitative Research Methods and R\&D. Bandung: Alfabeta.

Suliyanto. 2006. Business Research Methods. Yogyakarta: C.V. Andi.

Tzeng 2007. Evaluation of Intertwined Effects in E-Learning. China: Expert System With Applications.

Yumanita 2005. Ascarya Diana. indonesia: Looking for a Solution to Low Profit Sharing in Indonesian Islamic Banking. Bulletin of Monetary Economics and Banking. 